\title{
Influence of Maternal Factors on Mode of Delivery and Birth Weight in Urban Pregnant Women
}

\author{
Vijayalaxmi K. G. and Asna Urooj* \\ ATIC, University of Agricultural Sciences, Bangalore 560 024, Karnataka, India \\ *Department of Studies in Food Science and Nutrition, University of Mysore \\ Manasagangotri, Mysore 570 006, Karnataka, India
}

KEYWORDS Pregnant Women. Body Mass Index. Mode of Delivery. Birth Weight. Morbidity. Nutrition Education

\begin{abstract}
Pregnancy is one of the most critical and unique period in a woman's life cycle. The present longitudinal study was undertaken to assess the influence of certain factors on mode of delivery and birth weight in urban pregnant women visiting hospitals for regular ANC check-up. The sample size included 100 pregnant women. Information was collected on age, type of family, education, income, parity, medical history, obstetric history, meal pattern and morbidity status by personal interview method using questionnaire. Mode of delivery was noted using hospital records. Birth weight of neonates was taken within two days of birth. Majority of the subjects $(82 \%)$ were using mixed type of diet. non vegetarians. Fever was the most common ailment reported. The influence of the factors like maternal age and parity on mode of delivery and also the influence of maternal age and birth weight were found to be non significant. Significant association was observed between maternal age and the body mass index $(\mathrm{p}>0.05)$. The study revealed that the basic nutrition education is very essential for women in order to maintain a normal body mass index during the prime child bearing age.
\end{abstract}

\section{INTRODUCTION}

Pregnancy is one of the most critical and unique period in a woman's life cycle. It is regarded as 'welcome event' for successful womanhood. Data from NNMB show that a significant percentage of adult women in the reproductive period are at high risk with increased likelihood of obstetric complications and low birth weight offspring. Despite improvements in life expectancy, percent reduction in infant mortality and child mortality over the years, there is high proportion of low birth weight infants (Kharade and Antony 2002).Further low birth weight babies tend to become insulin resistant and likely to develop insulin resistance syndromes, diabetes, hypertension and abnormal blood lipids in the later part of their life (Thame et al.1997). Mode of delivery and birth weight are considered as one of the important and reliable parameters in the evaluation of pregnancy and neonatal well being. A number of factors influence the pregnancy outcome such as age of mothers, educational status, food habits, earlier reproductive

Address for Correspondence:

Vijayalaxmi. K.G., Assistant Professor,

ATIC, Directorate of Extension, University of

Agricultural Sciences, Hebbal Campus,

Bangalore 560 024, Karnataka, India

Telephone: 23549687/23513093 performance etc. Hence, the present longitudinal study was undertaken to know the influence of certain factors on mode of delivery and birth weight.

\section{MATERIALS AND METHODS}

A total of 100 pregnant women visiting private and Government Hospitals of Bangalore urban were selected on the basis of their willingness to participate in the study. The information on age, type of family, education, income, parity, family medical history, previous obstetric history, dietary habits, and morbidity status etc. were collected by using personal interview method. The measurements for height and weight of the pregnant women were taken as per the standard procedures. The body mass index was calculated using the standard formula. The birth weight of the infants was taken recorded in hospital within two days. Mode of delivery was noted from hospital records.

\section{RESULTS AND DISCUSSION}

More number of women in the study group were in the young, in the prime reproductive period age category. i.e. $<22$ years of age (37\%) followed by $>25$ years $(32 \%)$. Maximum women belonged to Hindu religion (98\%). Majority of women were 
living in joint family system (54\%) and studied upto SSLC only.The monthly family income was about Rs.4,000/- in majority of women (46\%) in the present study population (Table 1).

Table 1: Classification of respondents by characteristics

\begin{tabular}{llrr}
\hline Characteristics & \multicolumn{1}{c}{ Category } & \multicolumn{2}{c}{ Respondents } \\
\cline { 3 - 4 } & & Number & Percent \\
\hline Age group & <22 years & 37 & 37.0 \\
& 23-25 years & 31 & 31.0 \\
Religion & $>25$ years & 32 & 32.0 \\
& Hindu & 98 & 98.0 \\
Type of Family & Christian & 2 & 2.0 \\
& Nuclear & 46 & 46.0 \\
Education & Joint & 54 & 54.0 \\
& <SSLC & 54 & 54.0 \\
Income & PUC & 21 & 21.0 \\
& Graduation & 25 & 25.0 \\
& <Rs4000 & 46 & 46.0 \\
& Rs4000-8000 & 33 & 33.0 \\
Total & $>$ Rs8000 & 21 & 21.0 \\
\hline
\end{tabular}

Among the subjects, $78 \%$ were multipara and $22 \%$ were primigravidae. Still births were not reported by maximum number of subjects $(97 \%)$ (Table 2).

Table 2: Number of pregnancy and pregnancy outcome of respondents

\begin{tabular}{llrr}
\hline Characteristics & Category & \multicolumn{2}{c}{ Respondents } \\
\cline { 3 - 4 } & & Number & Percent \\
\hline No of Pregnancy & No & 22 & 22.0 \\
& 2-Jan & 53 & 53.0 \\
\multirow{4}{*}{ No of still births } & 4-Mar & 25 & 25.0 \\
& Nil & 97 & 97.0 \\
No of living children & One/Two & 3 & 3.0 \\
& No & 65 & 65.0 \\
& One & 29 & 29.0 \\
Total & Two & 6 & 6.0 \\
\hline
\end{tabular}

Information elicited on the general dietary pattern of the subjects indicated that majority $(82 \%)$ of the subjects were using a mixed type of diet consisting of non-vegetarian food preparations either once a week or occasionally. An appraisal of the regularity of meals revealed that most of them were regular in their food intake.Thier meal pattern comprised of one breakfast and two meals (Table 3).

Table 4 depicts that $16 \%$ of the subjects were obese, $6 \%$ were hypertensive, $3 \%$ were diabetic and only $1 \%$ had migraine problems during the previous pregnancies. Table also shows family
Table 3: Dietary habit of respondents

\begin{tabular}{llrr}
\hline Characteristics & Category & \multicolumn{2}{c}{ Respondents } \\
\cline { 3 - 4 } & & Number & Percent \\
\hline Type of Diet & Vegetarian & 18 & 18.0 \\
& Mixed & 82 & 82.0 \\
Eat in between & Yes & 19 & 19.0 \\
meals & No & 81 & 81.0 \\
Skip of omit meals & Yes & 39 & 39.0 \\
& No & 61 & 61.0 \\
Eat food outside & Yes & 37 & 37.0 \\
home & No & 63 & 63.0 \\
\hline Total & & 100 & 100.0 \\
\hline
\end{tabular}

Table 4: Medical history of respondents $(N=100)$

\begin{tabular}{lccccc}
\hline Medical History & \multicolumn{4}{c}{ Response } \\
\cline { 2 - 3 } & \multicolumn{1}{c}{ Family } & Members & & Respondents \\
\cline { 2 - 3 } \cline { 5 - 5 } & Number & Percent & & Number & Percent \\
\hline Hypertension & 29 & 29.0 & 6 & 6.0 \\
Diabetes & 23 & 23.0 & 3 & 3.0 \\
Obesity & 9 & 9.0 & 16 & 16.0 \\
Migraine & 2 & 2.0 & 1 & 1.0 \\
\hline
\end{tabular}

disease history of the subjects. Majority of the family members were found to suffer from chronic diseases such as hypertension $29 \%$, diabetes $23 \%$ and obesity $9 \%$. Among the families only $2 \%$ had the migraine problem.

The term 'morbidity' refers to the state of being diseased affecting the way of life of human beings. During pregnancy, morbidity status not only affects mothers but also the offspring. Hence in the present study, the morbidity status of the mothers was assessed. The common ailments expressed by the majority of subjects during pregnancy were fever $(82 \%)$, diarrhea $(11 \%)$, cough (9\%), urinary tract infection $(1 \%)$ and others (2\%) (Table 5).

Table 5: Morbidity status of respondents during the course of pregnancy

\begin{tabular}{lrr}
\hline Morbidity status $^{l}$ & \multicolumn{2}{c}{ Respondents } \\
\cline { 2 - 3 } & Number & Percent \\
\hline Fever & 82 & 82.0 \\
Cough & 9 & 9.0 \\
Diarrhea & 11 & 11.0 \\
Urinary tract infection & 1 & 1.0 \\
Others & 2 & 2.0 \\
\hline
\end{tabular}

${ }^{l}$ Multiple response

It was observed that maximum number of women had normal delivery $49 \%$. Cessarian as mode of delivery was comparatively more among women of more than 25 years age groups (56.5\%). 
A study has reported more number of cesarean deliveries with urban women than rural (Easwaran and Sathiyanayaki 1995). Many studies have observed that the risk of cesarean deliveries increases with greater maternal age (Mukho padhyay et al. 1992; Witter et al.1995; Ecker et al. 2001; Goldman et al.2005). However, the association between age-group and mode of delivery was statistically non-significant (Table 6).

From Table 7 , it can be seen that the association between order of pregnancy and mode of delivery was non significant. as well as the association between mode of delivery and birth weight of the baby were statistically Nonsignificant. The findings are in agreement with earlier reports George et al. (2003) stating who have reported that parity as such had no direct influence on the birth weight of the baby. Contradictory results were also reported grand multiparity is at risk (Bai et al. 2002). But in the present study, the nonsignificant association found was may be due to less sample size in the higher order of pregnancy.

The non-significant association was also observed between age-group and birth weight of the infants (Table 8). The study group included women aged between 20-30 years. According to studies the relative risk of delivering low birth weight babies was more among mothers who were below the age of 20 years or above 30 years (Padte et al. 1989; George et al. 2003).

Somatic status reflects the body size as influenced by several factors, most important being heredity, environment and diet. Nutrition forms the core which influences maternal weight and height. These two measurements are used to compute the body mass index (BMI), an index of nutritional status of adults.BMI is a good index to assess the nutritional status of women in pregnancy as well as through out 1pregnancy. It has long been recognized that in adult life, with

Table 6: Association between age group and mode of delivery

\begin{tabular}{|c|c|c|c|c|c|c|c|c|}
\hline \multirow{3}{*}{$\begin{array}{l}\text { Number of } \\
\text { pregnancy }\end{array}$} & \multicolumn{8}{|c|}{ Mode of delivery } \\
\hline & \multicolumn{2}{|c|}{ Caesarian } & \multicolumn{2}{|c|}{ Normal } & \multicolumn{2}{|c|}{ Induced labor } & \multicolumn{2}{|c|}{ Combined } \\
\hline & $n$ & $\%$ & $n$ & $\%$ & $n$ & $\%$ & $n$ & $\%$ \\
\hline$<22$ years & 9 & 33.3 & 14 & 51.9 & 4 & 14.8 & 27 & 100 \\
\hline $23-25$ years & 12 & 42.9 & 14 & 50.0 & 2 & 7.1 & 28 & 100 \\
\hline$>25$ years & 13 & 56.5 & 10 & 43.5 & 0 & 0.0 & 23 & 100 \\
\hline Total & 34 & 43.6 & 38 & 48.7 & 6 & 7.7 & 78 & 100 \\
\hline
\end{tabular}

Table 7: Association between number of pregnancy and mode of delivery

\begin{tabular}{|c|c|c|c|c|c|c|c|c|}
\hline \multirow[t]{3}{*}{ Age group } & \multicolumn{8}{|c|}{ Mode of delivery } \\
\hline & \multicolumn{2}{|c|}{ Caesarian } & \multicolumn{2}{|c|}{ Normal } & \multicolumn{2}{|c|}{ Induced labor } & \multicolumn{2}{|c|}{ Combined } \\
\hline & $n$ & $\%$ & $n$ & $\%$ & $n$ & $\%$ & $n$ & $\%$ \\
\hline One & 22 & 44.0 & 23 & 46.0 & 5 & 10.0 & 50 & 100 \\
\hline Two & 3 & 100.0 & 0 & 0.0 & 0 & 0.0 & 3 & 100 \\
\hline Three & 3 & 25.0 & 8 & 66.7 & 1 & 8.3 & 12 & 100 \\
\hline Four & 6 & 46.2 & 7 & 53.8 & 0 & 0.0 & 13 & 100 \\
\hline Total & 34 & 43.6 & 38 & 48.7 & 6 & 7.7 & 78 & 100 \\
\hline
\end{tabular}

$\chi^{2}$ Values $=7.147$ Ns NS: Non-Significant

Table 8: Association between age group and birth weight of the baby

\begin{tabular}{|c|c|c|c|c|c|c|c|c|}
\hline \multirow[t]{3}{*}{ Mode of delivery } & \multicolumn{8}{|c|}{ Birth weight of the baby } \\
\hline & \multicolumn{2}{|c|}{$<2.5 \mathrm{~kg}$} & \multicolumn{2}{|c|}{$2.5-3.0 \mathrm{~kg}$} & \multicolumn{2}{|c|}{$>3.0 \mathrm{~kg}$} & \multicolumn{2}{|c|}{ Combined } \\
\hline & $n$ & $\%$ & $n$ & $\%$ & $n$ & $\%$ & $n$ & $\%$ \\
\hline$<22$ years & 6 & 22.2 & 14 & 51.9 & 7 & 25.9 & 27 & 100 \\
\hline $23-25$ years & 6 & 21.4 & 18 & 64.3 & 4 & 14.3 & 28 & 100 \\
\hline$>25$ years & 6 & 26.1 & 11 & 47.8 & 6 & 26.1 & 23 & 100 \\
\hline Total & 18 & 23.1 & 43 & 55.1 & 17 & 21.8 & 78 & 100 \\
\hline
\end{tabular}

$\chi^{2}$ Values $=1.963^{\mathrm{NS}} \quad$ NS: Non-Significant 
Table 9: Association between age group and body mass index

\begin{tabular}{|c|c|c|c|c|c|c|c|c|}
\hline \multirow[t]{3}{*}{ Age group } & \multicolumn{8}{|c|}{ Body Mass Index (BMI) } \\
\hline & \multicolumn{2}{|c|}{ Under weight $(<18.4)$} & \multicolumn{2}{|c|}{ Normal (18.5-24.9) } & \multicolumn{2}{|c|}{ Over weight (25.0-29.9) } & \multicolumn{2}{|c|}{ Combined } \\
\hline & $n$ & $\%$ & $n$ & $\%$ & $n$ & $\%$ & $n$ & $\%$ \\
\hline$<22$ years & 14 & 51.9 & 12 & 44.4 & 1 & 3.7 & 27 & 100 \\
\hline $23-25$ years & 7 & 25.0 & 20 & 71.4 & 1 & 3.6 & 28 & 100 \\
\hline$>25$ years & 3 & 13.0 & 18 & 78.3 & 2 & 8.7 & 23 & 100 \\
\hline Total & 24 & 30.8 & 50 & 64.1 & 4 & 5.1 & 78 & 100 \\
\hline
\end{tabular}

$\chi^{2}$ Values $=9.943^{* *}$ Significant at $5 \%$ level

advancing years, body weights tend to rise due to change in body composition. Majority of the women had BMI in the normal range (64\%). This is probably due to the fact that the subjects were below 40 years old. The underweight pregnant were more in the age group $<22$ years $(52 \%)$ and over weight women were more in the age group $>$ 25 years $(8.7 \%)$. The influence of age on BMI was statistically significant at $5 \%$ level, showing an increasing trend in weight against the gradient of age (Table 9). Nerlekar et al. (1999) has reported that pregnancy outcome is influenced by mother's stature. The study reinforces the importance of normal weight not only to maintain good health but also to have better gestational outcome during pregnancy. It also envisages that the basic nutrition education is very essential for women in order to maintain the normal body mass index compulsorily during the prime child bearing age.

\section{REFERENCES}

Bai J, Wong FWS, Bauman A, Mohsin M 2002. Parity and pregnancy outcomes. Am J Obstet Gynecol, 186: 274-278

Easwaran PP, Sathiyanayaki KM 1995. Influence of maternal body mass index on birth weight. The Indian Journal of Nutrition and Dietetics, 32(1): 16.
Ecker JL, Chen KT, Cohen AP, Riley.L.E, Lieberman ES 2001. Increased risk of cesarean delivery with advancing maternal age: Indications and associated factors in nulliparous women. American Journal of Obstetrics and Gynaecology, 185: 883-887.

George, KA, Sreedevi R, Suresh Kumar N, Sarma SP 2003. A study on the influence of maternal factors on birth weight. The Indian Journal of Nutrition and Dietetics, 40: 291-296.

Goldman JC, Malone FD, Vidaver J, BallR H, Nyberg DA et al., 2005. Impact of maternal of maternal age on obstetric outcome. Obstetrics and Gynecology, 105: 983-990.

Kharade PP, Antony U 2002. Nutritional status and outcome of pregnancy in young and older mothers in Mumbai. The Indian Journal of Nutrition and Dietetics, 39(1): 26-30.

Mukhopadhyay,S. Gupta, H.P. and Das, K. 1992. Pregnancy after 30. The Journal of Obstetrics and Gynaecology of India, 42: 293-298.

Nerlekar JP, Nalwade VM, Reddy NS 1999. Effect of maternal factors on outcome of pregnancy. The Indian Journal of Nutrition and Dietetics, 36: 320324.

Padte K, Pal MN, Pavse J 1989. Review of teenage pregnancy in Goa. The Journal of Obstetrics and Gynaecology of India, 40: 472-474.

Thame M, Wilks RJ, Anderson, Mc.FN, Bennett FI, Forrester TE 1997. Relationship between maternal nutritional status and infants weight and body proportions at birth. European Journal of Clinical Nutrition, 51: 134-138.

Witter FR, Caulifield LE, Stoltzful RJ 1995. Influence of maternal anthropometric Status and Birth weight on the risk of caesarean delivery. Obstetrics and Gynecology, 85(6): 947-951. 